\title{
Intraseasonal Ensemble Forecasting for the Brazilian Northeastern
}

\author{
Cleber Souza Corrêa' \\ Fabricio Pereira Harter" \\ Gerson Luiz Camillo"II
}

\section{ABSTRACT}

This preliminary analysis, uses simulations performed by the National Centers for Environmental Prediction (NCEP) coupled forecast system model version 2 (CFSv2)/regional climate model RegCM-4.6, allowed to be observed in this work, the data analyzed were the information of the surface wind intensity, by the analysis and comparison of the simulations carried out for the Alcântara region on the coast of the state of Maranhão. These simulations were stored in the period from February to June 2018. The analysis sought to validate with ERA5 reanalysis data from the European Center for Medium-Range Weather Forecasts (ECMWF). The observed result shows great potential for use of prediction ensemble techniques, since in the observed results the smallest anomalies were observed in the intraseasonal ensemble prediction to the Alcântara region in the intensity wind, in comparison to the simulation without being ensemble, presenting greater deviations and when closer to the forecast, in itself, greater deviations presented. The intraseasonal Ensemble estimation ends up filtering the terms of high frequency, being the best estimate and presenting intraseasonal predictions more balanced.

Keywords: Intraseasonal Climate Forecast; Regional climate model; Dynamical Ensemble Forecast 


\section{Introduction}

This research seeks to analyze the behavior of the RegCM4.6 model, using as an initialization the global conditions the Seasonal climate forecast from CFSv2 model, programmed to represent the intraseasonal variability for the Brazilian northeast coast. This process is being simulated continuously every 15 days and its results stored. With these stored data, it was possible to analyze the variability of the initialization behavior and the results observed by the RegCM-4.6 Regional Climatic model. The main objective is to observe the CFSv2 / RegCM-4.6 simulation behavior using ensemble terms in the estimation. The intraseasonal forecast using regional climate models is an important research and development tool, Da Rocha, et al. (2012), De Souza, et al. (2016), Reboita, et al. (2017), Corrêa, et al. (2017), Llopart, et al. (2017) and Corrêa, et al. (2018). Therefore the use of intraseasonal forecasting needed, on the idea proposed by Gneiting and Raftery (2005), discussed in their perspective, a new approach--ensemble forecasting. It was introduced in the early 1990s. In this method, up to 100 different computer runs, each with slightly different starting conditions or model assumptions, are combined into a weather forecast. In concert with statistical techniques, ensembles can provide accurate statements about the uncertainty in daily and seasonal forecasting, their proposals to improve the modeling, statistical analysis, and visualization technologies for disseminating the ensemble results. In which, weather prediction has been transformed through the implementation of ensemble forecasts. The use of different methods for ensemble forecasting to perform a type of numerical or statistical modeling using stochastic models and other techniques, Sabeerali, et al. (2017), Wasyl \& Matthew (2017), Chen, et al. (2018) and Zang, et al. (2018). For the region of Maranhão, the modeling was applied to generate information about the vertical profile of the wind and the surface, in the work of Corrêa, et al. (2018). Its results were obtained using the outputs from the global NCEP climate forecast system (CFSv2) as initial and boundary conditions for the Regional Climate Model (RegCM4.6). His research was to analyze the performance in forecasting the sub-seasonal and seasonal climate from June to October 2017 in Alcântara Launch Center (ALC), located in northeastern Brazil. The study focused on wind and air temperature variables in the lower atmosphere. The predictions were validated with the ERA-Interim reanalysis. In the Alcântara region, the RegCM4.6 model presented a good performance in representing the monthly means of the variables under study, but in other regions of the domain, it showed higher significant deviations differences compared with ERA-Interim model. As currently, it is possible to validate the simulations performed with ERA5 reanalysis data that have advantages over the ERA-Interim. In the work of Albergel, et al.(2018), it is discussed the use of the ERA5 reanalysis in place of the reanalysis of the
ERA-Interim, and most improvements seem to come from a better representation of precipitation in ERA-5 reanalysis and the use of ERA-5 leads to improvements in the representation of surface variables related to the terrestrial water cycle. Therefore, this work seeks to analyze the stored simulations performed for the Alcântara region in the Brazilian Northeast, aiming to analyze the wind intensity data close to the surface. With these simulations, it was analyzed month by month and with three components, it was computed a predictive intraseasonal ensemble term, and it was validated with the ERA5 reanalysis and the error involved in the prediction simulated by the CFSv2 / RegCM-4.6 model was estimated.

\section{Methodology}

This work adopted the CFSv2 reanalysis data, which is operated by the National Centers for Environmental Prediction (NCEP), Saha, et al. (2014), as the initial and boundary condition from RegCM4.6 Giorgi et al. (2015). Search to use comparing the simulations performed with global data of the CFSv2, model with the reanalysis of the European Centre for Medium-Range Weather Forecasts (ECMWF) - ERA5 reanalysis data. This meteorological dataset, ERA5, provides estimates of atmospheric parameters such as air temperature, pressure, wind, humidity, and ozone at different altitudes, surface parameters such as rainfall, soil moisture, sea-surface temperature, all at a resolution of about 31 $\mathrm{km}$ worldwide, and information on wave height over the global oceans. More information about the ERA5 model can be found on the website: https://confluence. ecmwf.int//display/CKB/ERA5+data+documentation. This work aims to analyze the simulations of the CFSv2 / RegCM4.6 stored model, between February and June 2018, when it was operationalized in the Atmospheric Sciences Division of the Institute of Aeronautics and Space (IAS), intraer link (HTTP: //www.iae.cta .intraer / cfs /) whose products are available for use in intraseasonal forecasts of the vertical wind profile at the Alcântara Launch Center. Seeks to analyze the quality of these predictions in time and is used temporally distant simulations from 15 to 15 days with a total of 45 days with three simulations. As also a mean field of the CFSv2 model is generated and this mean simulation is composed of three time-distanced simulations every 15 days, and compared with the ERA 5 model reanalysis data, in a total of nine CFSv2 / RegCM-4.6 simulations. The simulations were analyzed for the CFSv2 / RegCM-4.6 model on the following dates, April 2018 with simulations of 15/02, 01/03 and 15/03, May 2018 with simulations of 15/03, 01/04 and 15/04 and June 2018 with simulations of $15 / 04,01 / 05$ and $15 / 05$, with initialization at 00 hours. The use of a simple statistical model with the simple average between the different simulations obtained with temporal displacement allows a minimization of the possible perturbations inherent to the CFSv2/RegCM-4.6 model. 
Table 1 Parameters used in Physics paramnamelist (regcm.in) in RegCM4.6 model

\begin{tabular}{cc}
\hline Parameter & Value \\
\hline Lateral boundary conditions scheme & $\begin{array}{c}\text { Relaxation, exponential technique, } \\
\text { Marbaix et al. 2003 }\end{array}$ \\
\hline Planetary Boundary Layer (PBL) scheme & Holtslag PBL, Holtslag (1990) \\
\hline Cumulus Convection schemes & Grell 1993 \\
Over land & Emanuel 1991 \\
\hline Over ocean & Explicitmoisture (SUBEX, Pal et al. (2000)) \\
\hline Ocean Flux scheme & Zeng et al., 1998 \\
\hline Ceng Ocean model roughness formula to used & Gregorian \\
\hline Calendar & CFSO1 \\
\hline Globdatparam dattyp & CFS01 \\
\hline Land surface model & Biosphere-Atmosphere Transfer scheme (BATS) \\
\hline
\end{tabular}

Figure 1 The topography (meters) and the domain used in the test simulations of RegCM4.6 with CFSv2, with the geographic center on the ALC. The geographical location of the ALC is marked with a black dot.

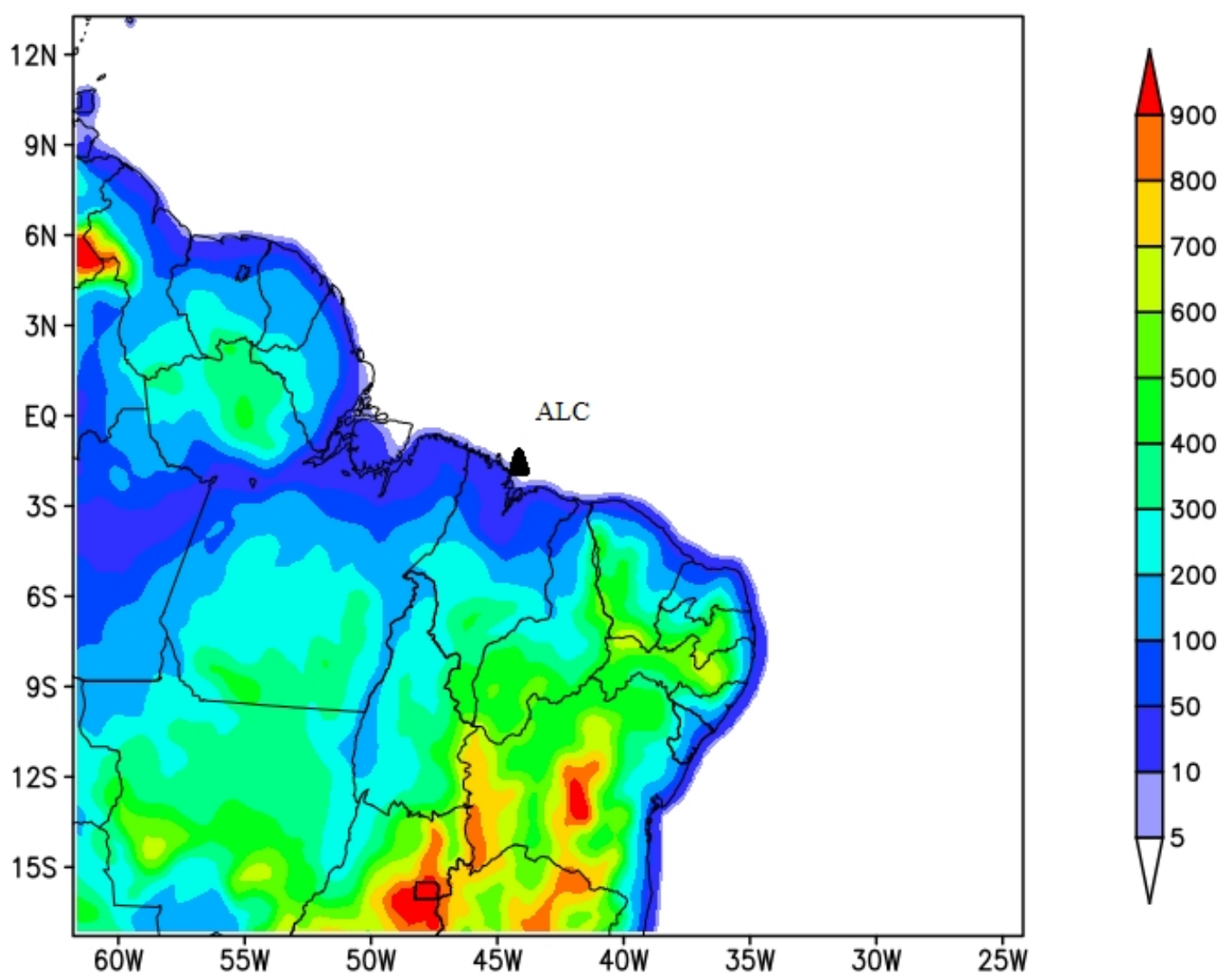




\section{Results}

Figure 2 shows the wind intensity with the monthly average of April (a), May (b) and June (c) with the information from the ERA5 reanalysis data and April (d), May (e) and June (f) are the monthly average wind intensity for these months simulated by the CFSv2 / RegCM-4.6 model. It presents small differences on the continent and shows greater differences on the ocean, but the simulation CFSv2/RegCM in the monthly average represented the main spatial characteristics of the wind intensity.

Figure 3 shows the difference between the ERA5 reanalysis model and the simulation of the CFSv2 / RegCM-4.6 model for the month of April 2018. Figure (a) is an anomaly with the difference between the ensemble, with the average of the three simulations with 15/02, 01/03 and 03/03. Figure (b) is the simulation with 45 days of time antecedence, (c) with 30 days of advance and (d) with 15 days. The largest differences in magnitudes of the wind intensity are given in figure (d) with 15 days of temporal advance.
Figure 4 shows the difference between the ERA5 reanalysis model and the simulation of the CFSv2 / RegCM-4.6 model for the month of May 2018. Figure (a) is an anomaly with the difference between the ensemble, with the average of the three simulations with $15 / 03$, $01 / 04$ and $15 / 04$. Figure (b) is the simulation with 45 days of time antecedence (15/03) and presented on the Atlantic Ocean a significant area of underestimation of the speed magnitude less than $4 \mathrm{~ms}-1$, (c) with 30 days of advance (01/04) and (d) with 15 days (15/04). The largest differences in magnitudes of the wind intensity are given in figure (d) with 15 days of temporal advance. On the Atlantic Ocean and the mainland, there were more than 4 ms-1 between the ERA5 and the CFSv2 / RegCM-4.6 model. Being that on the Atlantic ocean and on the continent overestimating with magnitudes of the order of $4 \mathrm{~ms}-1$. In this case figure (a) with the difference in the term ensemble had the smallest difference between the terms.

Figure 5 shows the difference between the ERA5 reanalysis and the simulation of the CFSv2 / RegCM-4.6 model for the month of June 2018. Figure (a) is an ano-

Figure 2 - The monthly average of the wind intensity for the months of April, May and June of 2018, with the figures April - (a), May - (b) and June - (c), ERA5 reanalysis data and April - (d), May - (e) and June - (f), for CFSv2 / RegCM-4.6 model, mean composite of the wind intensity by three simulations separated by 15 days in time.

(a)

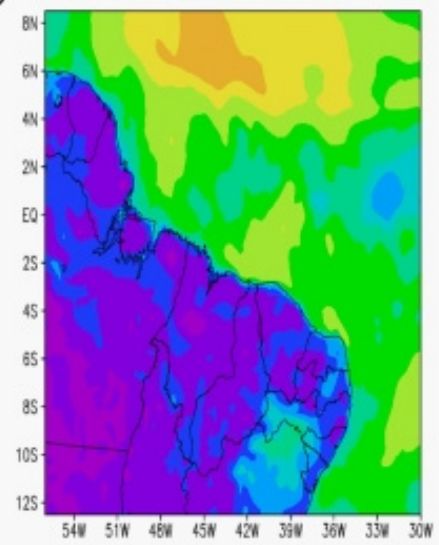

(d)

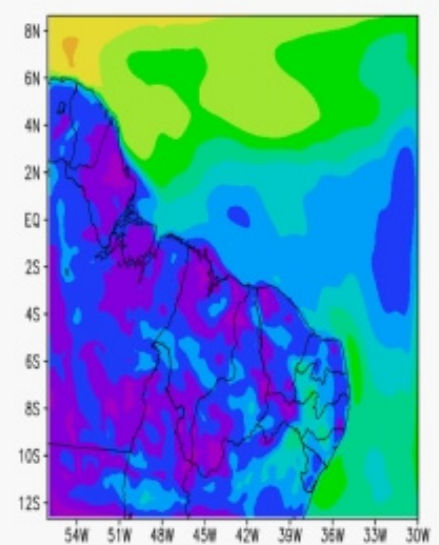

(b)

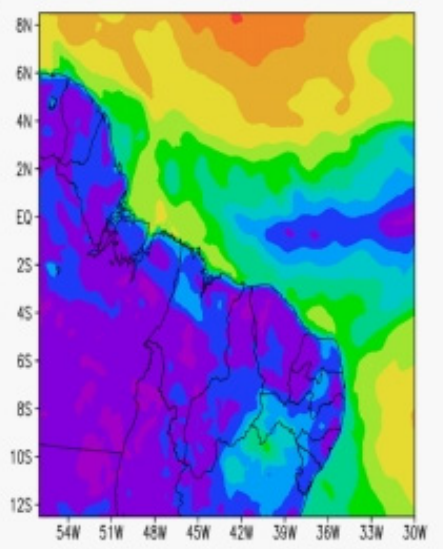

(c)

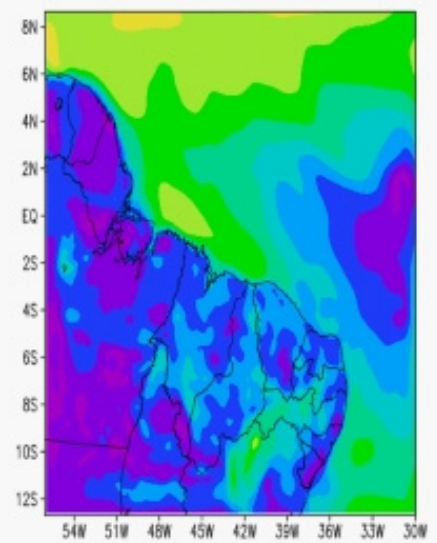

(c)

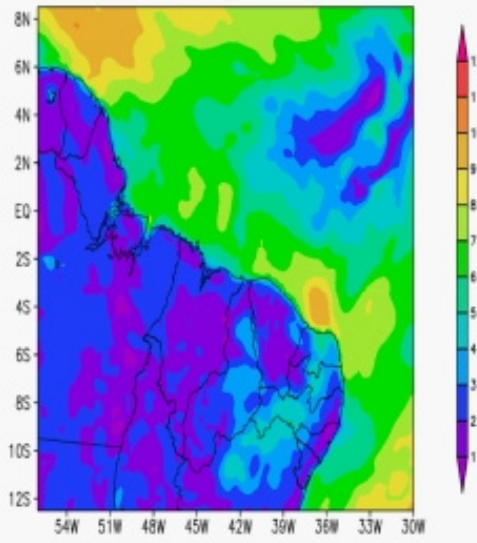

(f)

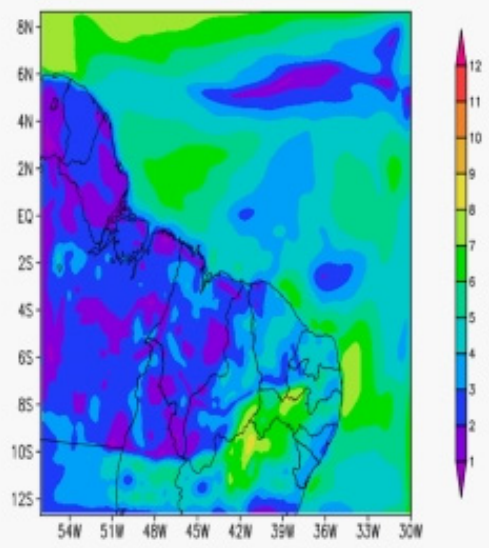


Figure 3 - show the anomaly between the ERA5 reanalysis data and CFSv2 / RegCM-4.6 model for the month of April 2018, figure (a) with the composite average of the three simulations (ensemble) and figure (b) with 45 days, figure (c) with 30 days and figure (d) with 15 days, showing the difference between intensity wind on the surface.

(a)

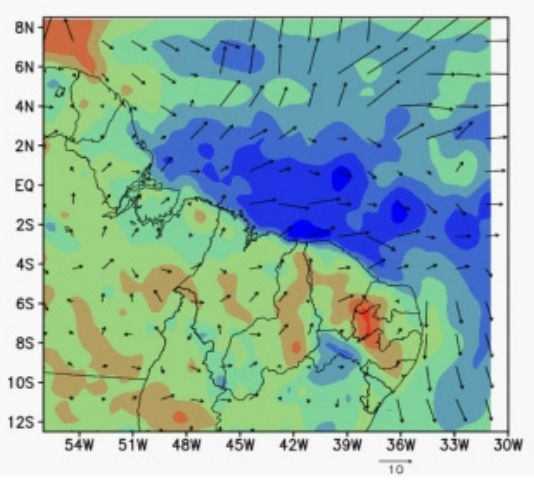

(c)

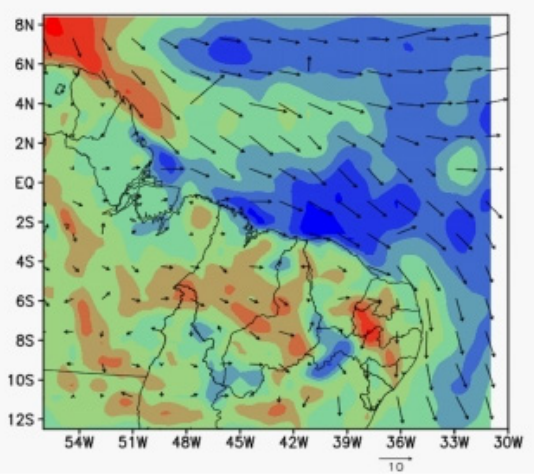

(b)

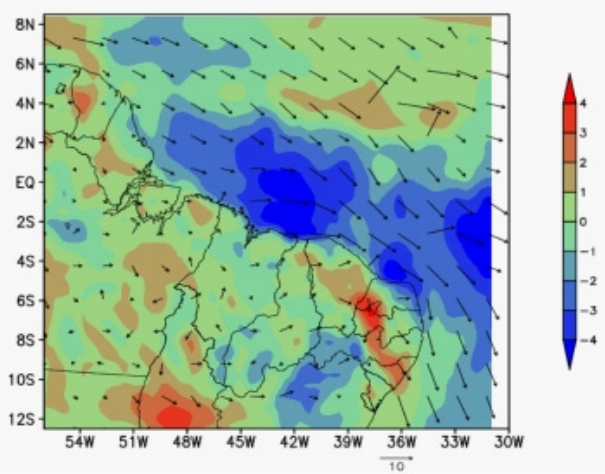

(d)

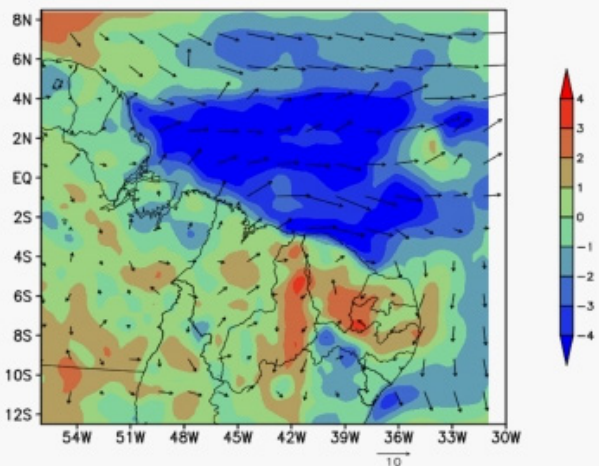

Figure 4 - show the anomaly between the ERA5 reanalysis data and CFSv2 / RegCM-4.6 model for the month of May 2018, figure (a) with the composite average of the three simulations (ensemble) and figure (b) - 45 days, figure (c) - 30 days and figure (d) - 15 days, showing the difference between intensity wind on the surface.

(a)

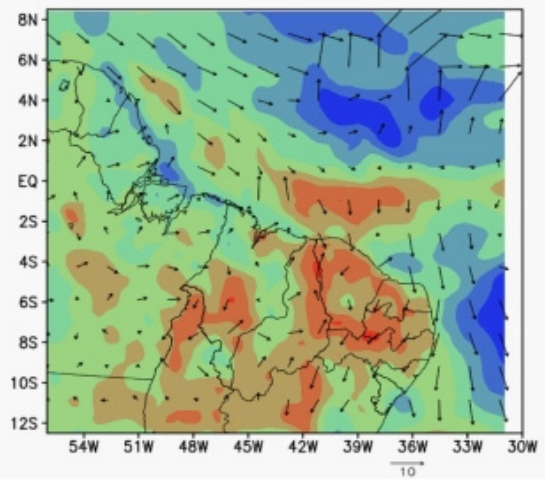

(c)

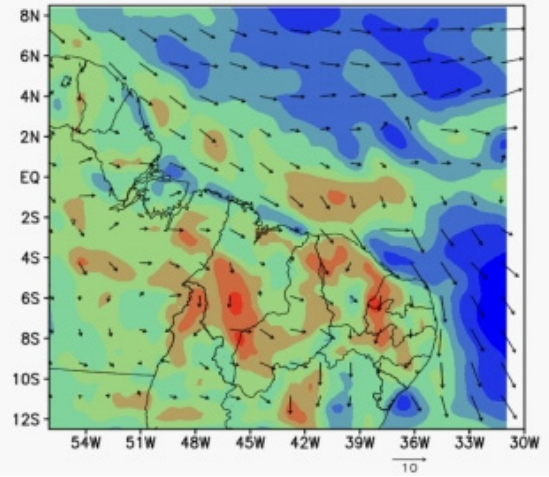

(b)

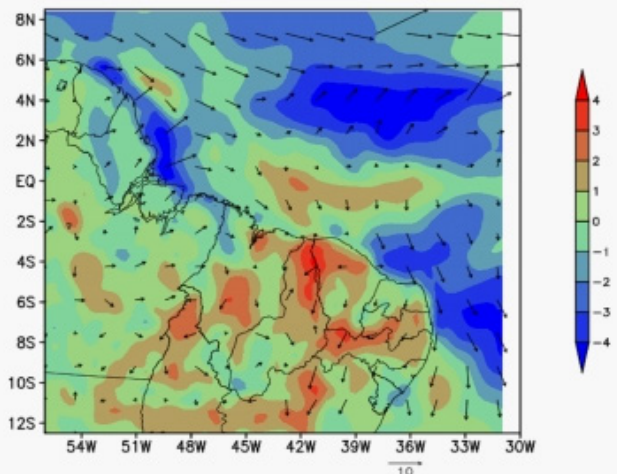

(d)

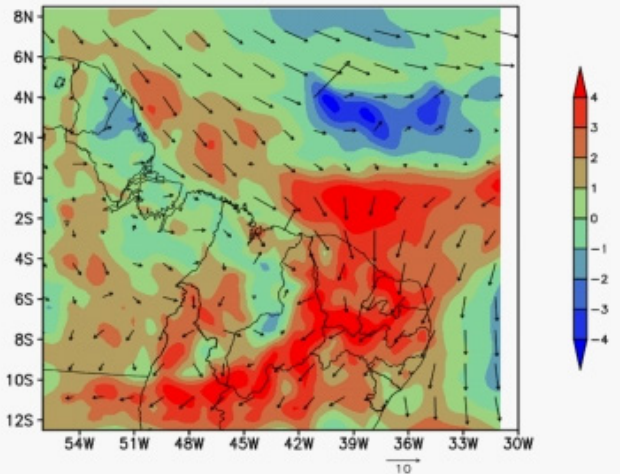


maly with the difference between the ensemble, with the average of the three simulations with 15/04, 01/05 and $15 / 05$. Figure (b) is the simulation with 45 days of time antecedence (15/04), (c) with 30 days (01/05) and (d) with 15 days (15/05). In figure (c) with 30 days of temporal advance the largest differences in magnitudes of the wind intensity. On the Atlantic Ocean and the mainland, there were more than $4 \mathrm{~ms}-1$ between the ERA5 and the CFSv2 / RegCM-4.6 model. In the Atlantic Ocean, the underestimation of the magnitude of wind velocity with magnitudes of $4 \mathrm{~ms}-1$, was well characterized. In this case, the figure (a) again with the term ensemble had the smallest differences between the terms. The different initiations of the CFSv2 model show small differences in their updates and when the term composite ensemble is calculated, these differences are minimized.

The analysis of the results shows a behavior of the CFSv2 model in each 15 day period with significant changes in the global initialization, showing differences in the assimilated forcing, and consequently affecting the results in the domain of the studied region, the Brazilian northeast.

Figure 5 - It shows the anomaly between the ERA5 reanalysis data and CFSv2 / RegCM-4.6 model for the month of June 2018, figure (a) with the composite average of the three simulations (ensemble) and figure (b) - 45 days, figure (c) - 30 days and figure (d) - 15 days, showing the difference between the wind intensity on the surface.

(a)

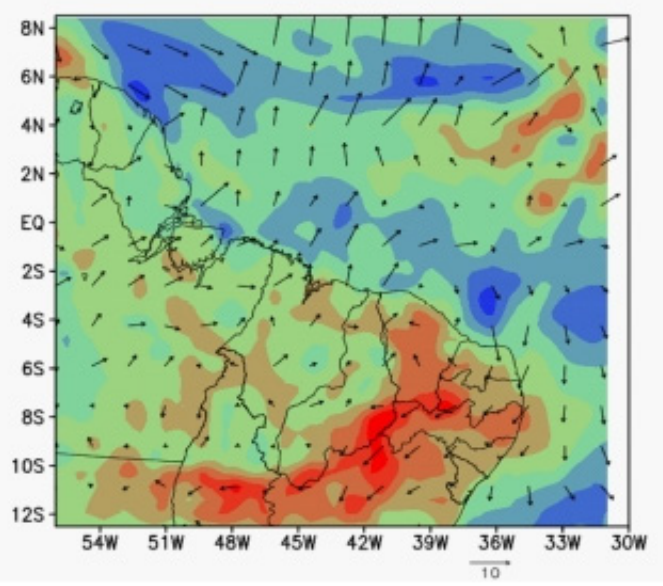

(c)

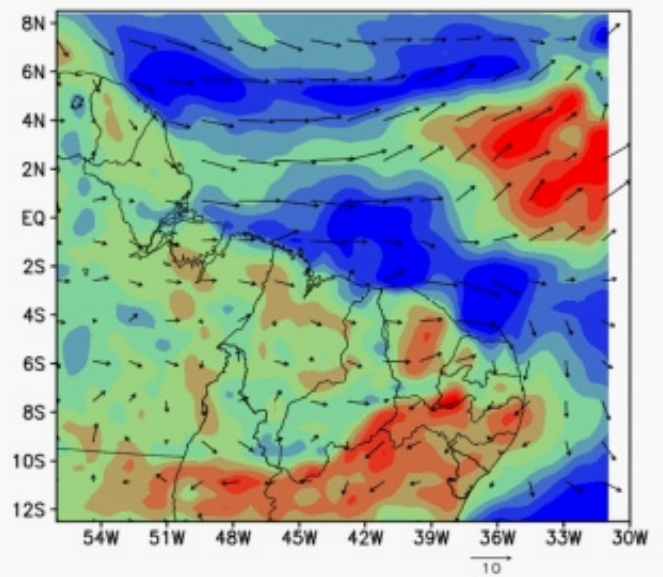

(b)

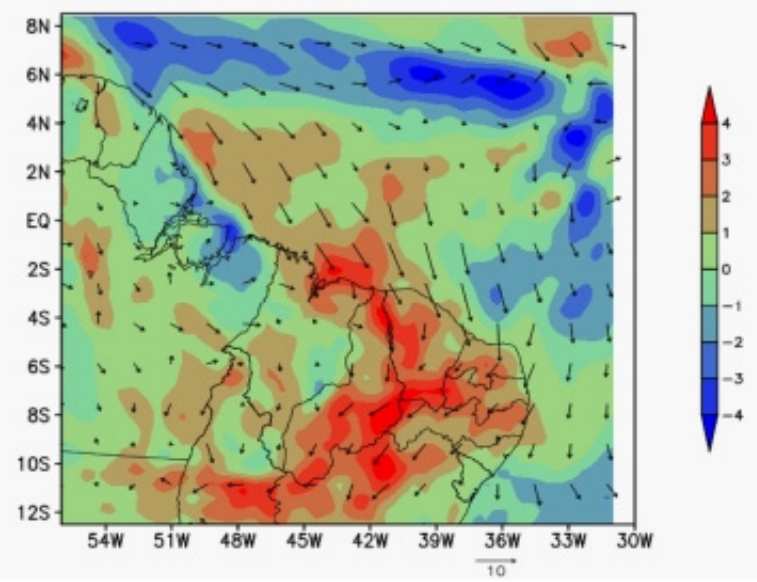

(d)

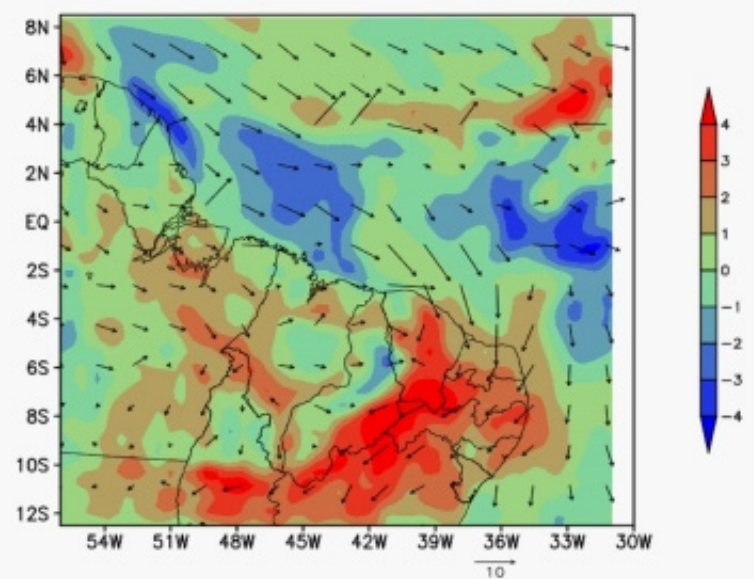




\section{Conclusions}

This work has the prospective focus on the use of ensemble simulations for the wind in the Alcântara, Maranhão, region. The use of intraseasonal predictions presented results that showed a better estimate with the ensemble term than the term individually. Since there may be significant oscillations and perturbations that would affect the simulation, they are eventually minimized by the generation of the ensemble term allowing the estimation to show a more balanced final result and the representation of average dominant systems with intensity closer to that observed by the reanalysis of the ERA5. Other works will be performed with more variable and statistical analysis with probabilities involved in the simulations with the CFSv2 / RegCM-4.6 model, as well as statistical estimates of its variability.

\section{Acknowledgements}

The authors thank the support of the Instituto de Aeronáutica e Espaço (IAE).

\section{References}

Albergel, C., DUtra, E., MUNiER, S., CAlVET, J.-C., MUNOZ-SABATER, J., de ROSNAY, P., and BALSAMO, G.: ERA-5 and ERA-Interim driven ISBA land surface model simulations: which one performs better?, Hydrol. Earth Syst. Sci., (2018), 22, 3515-3532. https://doi.org/10.5194/hess-22-3515-2018

CHEN, N., AJ. MAJDA, CT. SABEERALI, and RS. AJAYAMOHAN, Predicting Monsoon Intraseasonal Precipitation using a Low-Order Nonlinear Stochastic Model. J. Climate,(2018).31, 4403-4427, doi:https://doi. org/10.1175/JCLI-D-17-0411.1

CORRÊA, CS, CAMILLO, GL, COUTO, VM, FISCH, G, do NASCIMENTO CORREA, F., \& HÄRTER, F. Climate Forecasts at the Centro de Lançamento de Alcântara Using the Climate Model RegCM4. Journal of Aerospace Technology and Management, (2017). 9(1), 18-28. doi: 10.5028/ jatm.v9i1.649

CORRÊA, CS, REBOITA, MS, CAMILLO, GL, COUTO, VM and CORREA, FN. Intraseasonal Climate Forecast For The Alcântara Region In Northeastern Brazil. Revista Brasileira de Geografia Fisica. (2018). 11(6), 1963-1970. doi: 10.26848/rbgf.v11.6.p1963-1970.

DA ROCHA, RP ; CUADRA, SV ; REBOITA, MS ; KRÜGER, LF ; AMBRIZZI, T. ; KRISCHE, N . Effects of RegCM3 parameterizations on simulated rainy season over South America. Climate Research, (2012) v. 52, p. 253-265.

DE SOUZA, EB, CARMO, AMC, MOARES, BC, NACIF, A., da SILVA FERREIRA, DB, ROCHA, EJP., \& SOUZA,
PJDOP. Sazonalidade da Precipitação sobre a Amazônia Legal Brasileira: Clima Atual e Projeções Futuras Usando o Modelo RegCM4 (Seasonal Precipitation Over The Brazilian Legal Amazon: Climate Current and Future Projections Using RegCM4 Model). Revista Brasileira de Climatologia, 18 (2016).

EMANUEL, KA. A scheme for representing cumulus convection in large-scale models. J. Atmos. Sci. (1991) 48:2313-2329. doi:10.1175/1520-0469(1991)048<2313:AS FRCC $>2.0 . C O ; 2$

HOLTSLAG, AAM, DE BRUIJN, EIF, PAN H-L, A high resolution air mass transformation model for short-range weather forecasting. Mon. Wea. Rev.. (1990), 118:1561-1575. doi:10.1175/1520-0493(1990)118<1561:AHRAMT>2.0.CO;2

GIORGI, F, COPPOLA, E, SOLMON, F, MARIOTTI, L., SYLLA, MB, BI, X., ... \& TURUNCOGLU, UU. RegCM4: model description and preliminary tests over multiple CORDEX domains. Climate Research, (2012) 52, 7-29.

GIORGI, F., ELGUINDI, N., COZZINI, S., SOLMON, F.. Regional Climatic Model RegCM User's Guide Version 4.4. (2015).

GNEITING, T. \& RAFTERY, AF. Weather Forecasting with Ensemble Methods. Science. (2005). vol. 310, pp. 248-249. doi: 10.1126/science.1115255.

GRELL, GA. Prognostic evaluation of assumptions used by cumulus parameterizations. Monthly Weather Review, (1993), 121(3), 764-787.

LLOPART, M., Da ROCHA, RP, REBOITA, M. et al.. Sensitivity of simulated South America climate to the land surface schemes in RegCM4. Clim. Dyn.. (2017), 49: 3975-3987. https://doi.org/10.1007/s00382-017-3557-5.

MARBAIX, P, GALLEE, H, BRASSEUR, O, VAN YPERSELE, JP. Lateral boundary conditions in regional climate models: a detailed study of the relaxation procedure. Mon. Wea. Rev.. (2003), 131:461-479

PAL, JS, GIORGI, F, BI, X, ELGUINDI, N, SOLMON, F, RAUSCHER, SA., ... \& ASHFAQ, M. Regional climate modeling for the developing world: the ICTP RegCM3 and RegCNET. Bulletin of the American Meteorological Society, (2007), 88(9), 1395-1409.

PAL, JS., ELTAHIR, EA, \& SMALL, EE. Simulation of regional-scale water and energy budgetsRepresentation of subgrid cloud and precipitation processes within RegCM. Journal of Geophysical Research, (2000), 105(D24), 29579-29594.

PREIN, AF, \& GOBIET, A. Impacts of uncertainties in European gridded precipitation observations on regional climate analysis. International Journal of Climatology, (2017), 37(1), 305-327. 
REBOITA, MS, FERNANDEZ, JPR, LLOPART, MP, Da ROCHA, RP, PAMPUCH, LA, CRUZ, FT Assessment of RegCM4.3 over the CORDEX South America domain: sensitivity analysis for physical parameterization schemes. Clim. Res.. (2014), 60:215-234. https://doi.org/10.3354/ cr01239

REBOITA, MS., AMARO, TR \& De SOUZA, MR. Winds: intensity and power density simulated by RegCM4 over South America in present and future climate. Clim Dyn.. (2017) doi:https://doi.org/10.1007/s00382-017-3913-5

SABEERALI, CT, AJAYAMOHAN, RS, GIANNAKIS, D, et al., Extraction and prediction of indices for monsoon intraseasonal oscillations: an approach based on nonlinear Laplacian spectral analysis. Clim. Dyn. (2017), 49: 3031. doi: https://doi.org/10.1007/s00382-016-3491-y

SAHA, S., MOORTHI, S., WU, X., WANG, J., NADIGA, S., TRIPP, P., ...\&EK, M.. The NCEP climate forecast system version 2. Journal of Climate, (2014), 27(6), 2185-2208.

VERA, CS, ALVAREZ, MS, GONZALEZ, PLM, et al.. Seasonal cycle of precipitation variability in South America on intraseasonal timescales. Clim Dyn.. (2017), doi:https://doi.org/10.1007/s00382-017-3994-1

WASYL, D. \& MATTHEW, CW. Extended-Range Ensemble Predictions of Convection in the North Australian Monsoon Region. Frontiers in Earth Science Journal. (2017), vol. 5, p. 28. doi: 10.3389/feart.2017.00028.

ZHANG, Z; CAYAN, DR.; PIERCE, DW. Subseasonal to Seasonal Temperature Prediction Skill Over the California Region from Global Dynamical Forecasts. California's Fourth Climate Change Assessment, California Energy Commission. Publication Number: CCCA4-CEC-2018-010 2018.

ZENG, X., ZHAO, M., DICKINSON, RE.. Intercomparison of Bulk Aerodynamic algorithms for the computation of Sea surface fluxes using TOGA COARE and TAO data. Journal of Climate (1998), 11:2628-2644. doi:10.1175/15200442(1998)011<2628:10BAAF >2.0.CO;2

\section{Contribuição dos autores}

Cleber Souza Corrêa

Contribuições substanciais para a concepção do trabalho; redigiu o trabalho e realizou uma revisão substancial.

Fabricio Pereira Harter

Contribuições substanciais para a concepção do trabalho; redigiu o trabalho e realizou uma revisão substancial.

Gerson Luiz Camillo

Contribuições substanciais para a concepção do trabalho; redigiu o trabalho e realizou uma revisão substancial. 